\title{
Analysis and Research on Operating Mode of Voice Platform Based on Knowledge Payment
}

\author{
Jing Jia \\ Konkuk University, Seoul, South Korea \\ Email: jiajing@konkuk.ac.kr
}

How to cite this paper: Jia, J. (2019) Analysis and Research on Operating Mode of Voice Platform Based on Knowledge Payment. Open Journal of Social Sciences, 7, 397-404.

https://doi.org/10.4236/jss.2019.78029

Received: July 24, 2019

Accepted: August 26, 2019

Published: August 29, 2019

Copyright () 2019 by author(s) and Scientific Research Publishing Inc. This work is licensed under the Creative Commons Attribution International License (CC BY 4.0).

http://creativecommons.org/licenses/by/4.0/ (c) (i) Open Access

\begin{abstract}
In order to fully understand the current operating mode of the voice-based knowledge payment platform to discuss the future development trend of the voice-based knowledge payment, a preliminary analysis of the current mature knowledge payment platform operation mode in China is conducted through case analysis, comparative analysis, literature analysis, observation method, and other methods combined with Newcomb A-B-X balance model and Maletsk's "CMR" model, thereby providing reasonable suggestions for the development of a voice knowledge payment platform. The results show that as a new knowledge dissemination model, the new knowledge payment-based voice platform has specific innovations in terms of content production and communication structure. Its primary operation mode is to obtain the continuous consumption of users through the improvement of the three aspects of product quality and payment, mode, and traffic import. In summary, knowledge payment has changed the traditional way and ability to acquire knowledge, opened new ways to acquire knowledge, and provided new choices for users to learn knowledge. In the future, the development of the demand for knowledge payment is inseparable from the renewal of new technologies and the improvement of services. Paying attention to tail content, strengthening sociality and introducing new technologies are particularly important for the development of the platform. The trinity of content, social interaction and scenario also contribute to the healthy development of knowledge payment market.
\end{abstract}

\section{Keywords}

Knowledge Payment, Voice, Effect, Dissemination, Operational Model

\section{Introduction}

Both human development and social progress are inseparable from the dissemi- 
nation and sharing of knowledge [1]. Before the arrival of the shared economy, the dissemination and sharing of knowledge are mainly free [2]. With the spread of new technologies, different platforms for knowledge dissemination, exchange and sharing have emerged, which greatly improves the efficiency of knowledge dissemination and broadens the public's vision [3]. Using different knowledge payment platforms to share payment knowledge has been tried [4]. In today's sharing economy, many users have begun to use different knowledge payment platforms to pay for knowledge sharing [5].

With the improvement of the national economy and the development of the times, users have become more and more receptive to knowledge payment platform from exclusion [6]. Therefore, all kinds of knowledge payment platforms also try their best to find new operation modes to attract users and new knowledge transformation methods. As a result, a new generation of voice knowledge payment platform, represented by Zhihu, comes into being as the times require [7]. In the past, Sina's iask and Baidu knows, which focus on sociality, sharing and knowledge, belong to the traditional knowledge dissemination platform [8]. Since 2016, such as short reviews, Zhihu, Himalayan FM and so on, all belong to a new generation of knowledge question and answer platform. These platforms are also social, shared and knowledgeable, but at the same time, they are more innovative, such as the additional forms of question and answer and voice response, as well as the introduction of a new mode of payment for knowledge [9].

Based on the above background, through the preliminary deconstruction of the relatively mature knowledge payment platform in China, in this study, the operation mode of the voice knowledge payment platform is summarized, so as to provide inspiration for the development of the platform, and provide a new theoretical basis for the future development of voice knowledge payment. The research innovation of this paper is not only the application of various research methods and models in the analysis of the operation mode of the voice payment platform but also the detailed analysis of the current multiple platform models. The research of this paper has important reference value for the subsequent research.

\section{Methodology}

\subsection{Newcomb A-B-X Balance Model and Malezke CMR Model}

As shown in Figure 1, in the A-B-X model, A represents a cognitive person, B represents the cognitive another party, and $\mathrm{X}$ represents the third party. Each of the three letters represents a triangle, and they are interrelated and independent. A, B and X constitute a system. If there is an imbalance within the system, then in order to achieve balance, changes must take place within the system, from imbalance to equilibrium. If the equilibrium state is reached, that is $\mathrm{A}-\mathrm{X}=\mathrm{B}-\mathrm{X}$, the following two conditions must be met. First, $\mathrm{A}$ and $\mathrm{B}$ have the same strong tendency towards $\mathrm{X}$. Second, $\mathrm{X}$ has openness and circulation to $\mathrm{A}$ and $\mathrm{B}$. In this cognitive system, the position of $\mathrm{A}$ and $\mathrm{B}$ can be changed if the connection be- 
tween reactions changes. A can represent both the cognitive person and the cognitive object.

Combined with the analysis of A-B-X balance mode, it can be seen that the process of voice knowledge dissemination is also a specific process in which two or more participants agree or inconsistent on a certain knowledge; the final communication effect is the effect of multiple factors competing together, and the reason participants are attracted to the same knowledge platform is the common interest in a topic. Therefore, for the study of the content level of voice knowledge, the production of knowledge content cannot be regarded as a simple linear communication, or only the single role of knowledge dissemination in knowledge production; instead, it is a comprehensive investigation in a specific communication environment, such as the impact of audience participation on platform content, the constraints of platform rules on content, and the impact of paid models on content production.

As can be seen from Figure 2, in Maletsk's mode of communication, there are four main factors that influence the behavior of the communicators. The main body of the communication is influenced by many factors, including social and cultural norms and legal control, as well as the pressure or restraint of publicity of media content, as well as the restraint of self-image cognition of the main body of the communication. Similarly, the recipient orientation of the four elements will

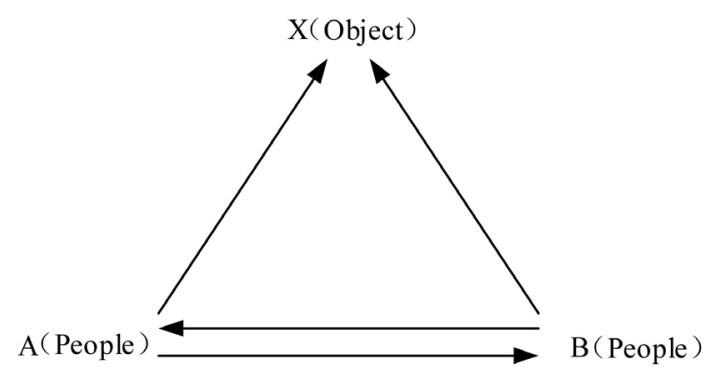

Figure 1. Newcomb A-B-X schematic diagram.

Spontaneous Feedback from Receiving

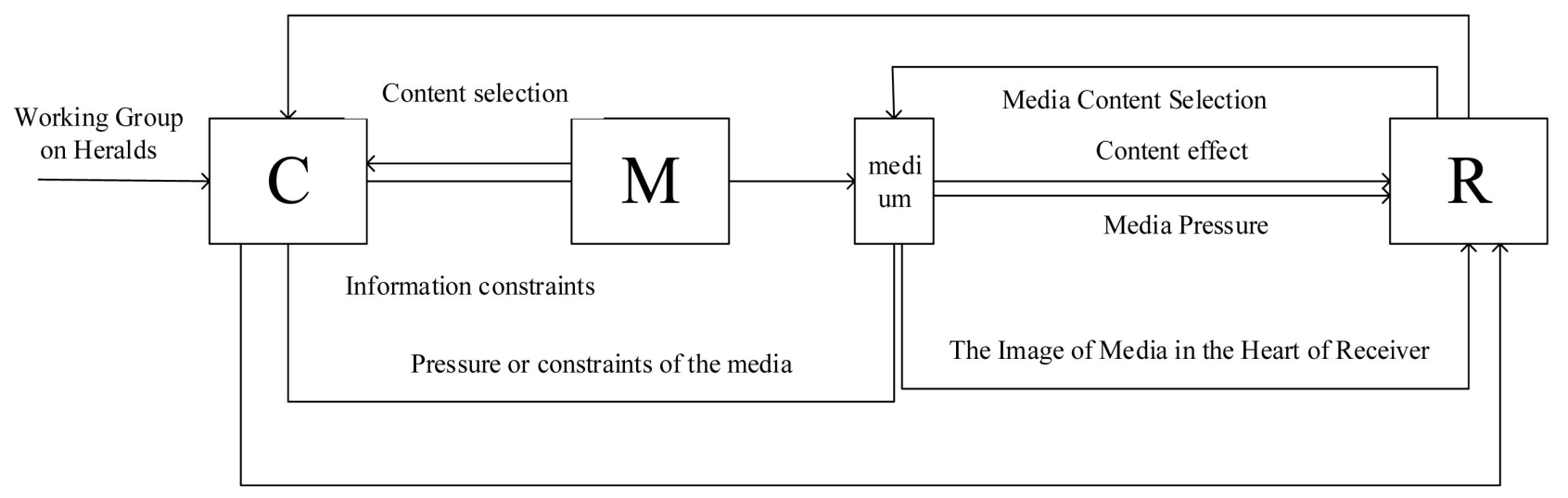

The image of the recipient in the hearer's mind

Figure 2. Maletsk's “CMR” model. 
also be affected by many factors. For example, the background of the recipient and the image of the media in the hearer's mind make the recipient unable to choose a large amount of information independently. Under the "CMR" mode, the media will select and organize the main content of information dissemination subject. At the same time, the pressure of the media will affect the subject of communication and the recipient of information. Information recipients will choose content passively under the pressure and constraints of the media.

\subsection{Payment Model of Voice Knowledge Payment Platform}

Real-time voice interaction on live platform is a typical one-to-many payment mode. All users who share a common interest in a topic will spontaneously organize a topic, and then design the content brief and outline of the topic. Starting with Live, they can participate in Live when they pay successfully. Speakers deliver live speeches in the form of live voice transmission. They teach courses in the form of voice, text and image, and interact in real time while learning. Zhihu Live brings offline courses online, expands the audience, increases the freedom to acquire knowledge, and allows users to participate in courses at any time, and anywhere.

Subscription means subscribing content on behalf of the user. Subscriptions can include courses, books, meetings, etc. on existing payment platforms. "iget" belongs to a typical payment mode of subscription. "iget" is a new knowledge service platform launched in 2015. It suggests that users use fragmented time to acquire knowledge and provide knowledge to users through excellent courses, columns of famous people and daily listening. "iget" makes use of the closed residential mode to provide knowledge content with a certain level and quality, cooperates with invited guests, improves independent knowledge products, and adopts platform sharing and business cooperation mode of resident guests to achieve the goal of mutual benefit and win-win. "iget" has many subscriptions, covering economics, science, the workplace, modern technology and finance. In recent years, the number of users who have access to the platform has continued to grow.

A typical example of scenario knowledge payment is Himalayan FM. Himalayan FM has a wide range of content categories, including radio, audio books, novels, music programs and paid subscription channels. Himalaya accounts for $70 \%$ of the best-selling audio copyright in the market and attracts a large number of users to listen to it. Among them, there are two typical scenario knowledge paid audio products. One is "Speak Well", which provides an eight-minute audio course, including communication, debate, speech, persuasion, negotiation, etc., so as to provide users with a series of vocabulary to meet the needs of life scenarios. The other is "elementary school questions". Users can buy 12 packages of products in different fields, each containing 10 audio pieces of 6 - 8 minutes.

Table 1 and Figure 3 show the distribution of TOP100 content type in payment knowledge rank. 


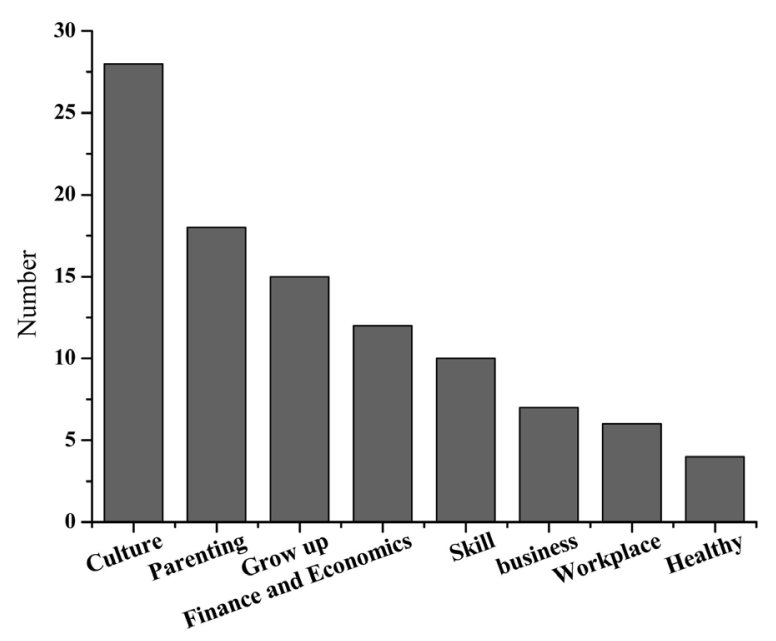

Figure 3. Distribution of TOP100 content type.

Table 1. Distribution of TOP100 content type in payment knowledge rank.

\begin{tabular}{ccccccccc}
\hline Content type & Culture & Parenting & Grow up & $\begin{array}{c}\text { Finance and } \\
\text { economics }\end{array}$ & Skill & Business & Workplace Health \\
\hline Number & 28 & 18 & 15 & 12 & 10 & 7 & 6 & 4 \\
\hline
\end{tabular}

\section{Results and Discussion}

\subsection{Consumer Group and Behavior Model of Voice Knowledge Payment Platform}

The elite stratum refers to the outstanding talents who have received higher education and have certain background and social orientation. The knowledge created by these people is of high quality and professional. Many pay-for-knowledge voice platforms use elites to create professional content and attract users' attention. For example, the respondents in Zhihu who get the most "like", the respondents in Fenda who enter the "line", the invited guests in the "iget" platform and the speakers in the Himalayan FM pay column are all excellent talents in all walks of life, and they are all part of the elite class. Therefore, their knowledge content is more professional and credible.

Some celebrities or stars are also used to attract users' attention, thereby expanding the influence of brands or columns. For voice knowledge payment platform, celebrity effect can be regarded as a marketing measure. Using the psychology of celebrities and celebrities, such as the pursuit and worship of ordinary users, users can pay for knowledge content. Fan economy refers to the business income-generating behavior based on the relationship between fans and followers. Celebrities or stars can motivate fans to pay for a knowledge product in order to achieve economic benefits. At present, the fan economy has a broader understanding. Enterprises will have a specific theme or interest groups of fans together, and carry out various activities to attract fans, so as to transform the enthusiasm of fans into the power of payment and profit. Table 2_shows the group composition of Zhihu live payment platform. 
Table 2. Zhihu live payment platform group composition table.

\begin{tabular}{|c|c|}
\hline Live & Main group \\
\hline Psychology & $\begin{array}{l}\text { Master of psychology and above certificate, psychological } \\
\text { outpatient service on-the-job certificate }\end{array}$ \\
\hline Medical care and health & $\begin{array}{l}\text { Blue standard certification of the front desk, certificate of } \\
\text { relevant work and medical qualification certificate }\end{array}$ \\
\hline Finance and economics & CFA, CPA, FRM, RFC, CWMA certified lecturer, auditor \\
\hline Law & $\begin{array}{l}\text { Legal professional qualification certificate, court work certificate, } \\
\text { lawyer professional qualification certificate, lawyer }\end{array}$ \\
\hline Workplace & Hard or Soft Skills Certificate, etc. \\
\hline Education & $\begin{array}{l}\text { Certificate of passing a certificate of professional } \\
\text { title examination, etc. }\end{array}$ \\
\hline Life style & $\begin{array}{l}\text { Fitness coach, medical practitioner, interior decoration designer } \\
\text { certificate, photographic institution }\end{array}$ \\
\hline Traveling & $\begin{array}{l}\text { At least one travel note is marked as high-quality content in } \\
\text { Xianguan Tourist APP }\end{array}$ \\
\hline Music, movies and games & Certificates of practice related to this field, etc. \\
\hline Patent application & $\begin{array}{l}\text { Patent agent qualification certificate and intellectual } \\
\text { property management system certification auditor }\end{array}$ \\
\hline
\end{tabular}

\subsection{Problems and Promotion Suggestions of Voice Knowledge Payment Platform}

Although all kinds of voice payment platforms on the market are becoming mature, there are still many problems, such as the most typical communication quality problems and the problem of copyright and content homogenization. In all kinds of payment platforms for voice knowledge, it is difficult to guarantee the quality of knowledge dissemination and eliminate serious piracy because of the uneven quality of users. The intrinsic value, scarcity and irreplaceability of knowledge dissemination are the key factors affecting users' reading and subscription, and also the core competition of major knowledge payment platforms. At present, there is a certain degree of homogeneity in the content of voice knowledge payment platform in China. For example, whether it is Zhihu Live or Himalayan FM, or even "Fenda", the content of each platform mainly focuses on time management, career growth, investment and financial management. The domestic market has a certain reputation for the knowledge payment platform, and there may be some differences in the use of its functions, but the differences in content are not obvious.

In the future promotion of voice knowledge payment platform, first of all, it is necessary to cooperate in many ways. The government and relevant operational departments should formulate various rules and regulations to effectively standardize the network environment and development of the voice knowledge payment platform. Secondly, the technology of big data and cloud computing has become mature, and has been widely used in all aspects of life. Therefore, 
each voice knowledge payment platform can accurately divide and recommend knowledge products by using big data technology. Finally, based on the original operation mode, the platform needs to extend the dimension of operation, make use of the user's leading role, enhance the communication between online users, strengthen social relations, broaden the social circle of online users, and use celebrity effect to cultivate online core users, so that core users can lead to the healthy development of ordinary users.

\section{Conclusions}

In this study, the theory of Newcomb A-B-X balance model and Malezke CMR model is used to conduct preliminary deconstruction of the more mature knowledge payment platform in China, such as Himalayan FM, iget, Zhihu, Fenda and short review. Then, through specific case analysis, comparative analysis, literature analysis, observation and other methods, the operation mode of voice knowledge payment platform is summarized, and the future development trend of voice knowledge payment is proposed. Since 2018, as the public's sense of novelty in the voice knowledge payment industry has declined, the voice of doubt about the knowledge payment industry has gradually increased. Although the total number of users on each platform is still growing, the growth rate of leap users is slow, and even the repurchase rate and total usage time of knowledge-based payment applications have a significant downward trend. The decline of the voice platform based on knowledge payment has eliminated many voice knowledge payment platforms from this market.

Although the development of voice knowledge payment platform is facing great difficulties and there are many doubts, as a new way of content delivery and knowledge sharing, knowledge payment still plays a leading role in publishing and education. Knowledge payment is a derivative of sharing economic development up to now. It has completely changed the traditional way of acquiring knowledge, and also innovated the way of learning knowledge. It provides a new choice for users to acquire knowledge. If the various knowledge payment platforms gradually expand the core payment mode, with the user value mining as the center, and meet the diversified needs of users, it will be able to form a complete industrial form in the future. The research in this paper also has certain limitations, such as that it is impossible to analyze all the current voice payment platforms. However, the research in this paper has included all the mature voice payment platforms, which is of great significance for the subsequent research.

\section{Conflicts of Interest}

The author declares no conflicts of interest regarding the publication of this paper.

\section{References}

[1] Xiang, F., Liu, B., Management, S.O., et al. (2014) The Exploratory Research on the 
Construct of Enterprise's Knowledge Worker Employability Voice. Journal of Business Economics, 1, 29-42.

[2] Song, J.H., Kim, H.K., Park, S., et al. (2014) Developing Knowledge Creating Technical Education Institutions through the Voice of Teachers: Content Analysis Approach. Career \& Technical Education Research, 39, 79-99.

https://doi.org/10.5328/cter39.1.79

[3] Maxhuni, A., Muoz-Meléndez, A., Osmani, V., et al. (2016) Classification of Bipolar Disorder Episodes Based on Analysis of Voice and Motor Activity of Patients. Pervasive \& Mobile Computing, 31, 50-66. https://doi.org/10.1016/j.pmcj.2016.01.008

[4] Hao, H. (2016) The Voice of Chinese Health Consumers: A Text Mining Approach to Web-Based Physician Reviews. Journal of Medical Internet Research, 18, e108. https://doi.org/10.2196/jmir.4430

[5] Gaad, E. (2015) Look Who's Coming to School: The Emirati Student Voice in an Intervention-Based Study on Inclusion of Learners with Intellectual Disabilities in Emirati Mainstream Government Schools. Journal of Research in Special Educational Needs, 15, 130-138. https://doi.org/10.1111/1471-3802.12053

[6] Davies, M. (2018) “Doing” Persuading: Actively Constructing Knowledge, Voice and Self. Changing English, 25, 264-274.

https://doi.org/10.1080/1358684X.2018.1482738

[7] Chen, Z., Sun, J.L. and Yang, Y.P. (2018) The Research and Practice of Professional Knowledge Sharing and Service: A Case Study of the Geography, Resources, and Ecology Knowledge Service System. Journal of Resources and Ecology, 9, 218-226. https://doi.org/10.5814/j.issn.1674-764x.2018.02.012

[8] Ogbuabor, D.C. and Onwujekwe, O.E. (2018) Scaling-Up Strategic Purchasing: Analysis of Health System Governance Imperatives for Strategic Purchasing in a Free Maternal and Child Healthcare Programme in Enugu State, Nigeria. BMC Health Services Research, 18, 245. https://doi.org/10.1186/s12913-018-3078-x

[9] Loh, A.Z.H., Oen, K.Q.X., Koo, I.J.Y., Ng, Y.W. and Yap, J.C.H. (2018) Weight Management during Pregnancy: A Qualitative Thematic Analysis on Knowledge, Perceptions and Experiences of Overweight and Obese Women in Singapore. Global Health Action, 11, Article ID: 1499199. https://doi.org/10.1080/16549716.2018.1499199 